\title{
Aktivitas Urinasi dan Penampakan Ekor Berdiri Tegak Sebagai Indikator Tingkah Laku Kawin Rusa Timor (Cervus timorensis) Betina di Penangkaran Aro-M Manokwari
}

\section{Urinating and an Upright-Tail Appearance as Indicators of the Female Timor Deer (Cerous timorensis) Mating Behavior in Aro-M Captive Facility, Manokwari}

\author{
Alfrida Gobay ${ }^{1)}$, Frandz Pawere ${ }^{2)}$, Freddy Pattiselanno ${ }^{2) *}$ \\ ${ }^{1)}$ Fakultas Peternakan Universitas Papua, Manokwari \\ ${ }^{2}$ Program Studi Budidaya Ternak Fakultas Peternakan Universitas Papua, Manokwari \\ J1. Gunung Salju, Amban, Manokwari 98314, Papua Barat. Indonesia
}

\author{
Article history \\ Received: Jan 3, 2020; \\ Accepted: Jun 14, 2020 \\ * Corresponding author: \\ E-mail: \\ f.pattiselanno@unipa.ac.id \\ DOI: \\ 10.46549/jipvet.v10i2.82
}

\begin{abstract}
A deeper knowledge regarding the biology of the reproduction of tropical deer in its natural habitat is limited. The appearance of a standing tail and increased urination behavior are sexual characteristics of female deer. This research aims to study the mating behavior of females based on urination activity and upright-tail appearance in female Timor deer. The results showed that the lowest urination frequency of female deer (12.37\%) occurred between 10.00 12.00, while the highest $(22.22 \%)$ was between $08.00-10.00$. The appearance of tails that stand upright most often occurs in $06.00-08.00(26.55 \%)$, and the lowest $(8.19 \%)$, observed at $12.00-14.00$. This study concludes that urination activity and appearance of upright tails was an indicator of the sexual desire of female deer to be mated by the male.
\end{abstract}

Keywords: Behavior; Captivity; Female deer; Mating; Urinating

\section{Abstrak}

Pengetahuan yang mendalam mengenai biologi reproduksi rusa tropik yang ditangkarkan pada habitat aslinya masih sangat terbatas. Penampakan ekor yang berdiri tegak dan tingkah laku urinasi yang meningkat merupakan ciri rusa betina yang sedang berahi. Penelitian ini bertujuan untuk mengetahui tingkah laku kawin berdasarkan aktivitas urinasi dan penampakan ekor berdiri tegak pada rusa timor betina. Hasil penelitian menunjukkan bahwa frekuensi urinasi rusa betina terendah $(12,37 \%)$ terjadi pada periode 10.00 - 12.00 sedangkan yang paling tinggi $(22,22 \%)$, pada periode 08.00-10.00. Penampakan ekor yang berdiri tegak paling sering terjadi pada periode $06.00-08.00$ yaitu $(26,55 \%)$, dan terendah $(8,19 \%)$, teramati pada pukul 12.00-14.00 wit. Berdasarkan hasil penelitian ini disimpulkan bahwa aktivitas urinasi dan penampakan ekor berdiri tegak dapat digunakan sebagai indikator birahi rusa berina yang siap untuk dikawini pejantan.

Kata kunci: Penangkaran; Rusa betina; Tingkah laku; Kawin; Urinasi

\section{PENDAHULUAN}

Salah satu faktor yang menentukan keberhasilan pengembangan rusa adalah teknik penangkaran dan manajemen, termasuk aspek reproduksi. Penelitian yang pernah dilakukan menunjukkan bahwa tingkat reproduksi rusa timor di penangkaran atau di luar habitat aslinya cukup tinggi (Ismail, 2012). Oleh karena itu dalam pengembangan program penangkaran, dianjurkan jumlah betina lebih banyak dibanding jantan karena satu ekor rusa jantan dapat mengawini empat ekor betina. Laju pertumbuhan populasi pada penangkaran 
rusa dengan sistem ranch lebih cepat yaitu 50\% per tahun jika dibandingkan dengan penangkaran skala kecil dengan sistem kandang (Garsetiasih dan Takandjanji, 2007).

Masalah utama dalam usaha penangkaran rusa adalah peralihan dari kebiasaan hidup liar di alam ke dalam suasana penangkaran serta kebiasaan rusa yang hidup berkelompok, sehingga dalam manajemen perkawinannya tidak bisa dikontrol dan berakibat pada kemungkinan terjadinya inbreeding yang tinggi (Drajat, 2002).

Upaya penangkaran rusa di Kabupaten Manokwari, awalnya berkembang dengan cara memelihara di pekarangan, lapangan rumput, pinggiran jalan dan beberapa tempat umum (Duwila, 2001; Pattiselanno et al., 2008). Kegiatan ini berlangsung dalam skala kecil dengan jumlah hewan peliharaan berkisar antara 1-3 ekor (Duwila, 2001; Pattiselanno, et al, 2008; Pattiselanno, 2013). Penangkaran rusa skala besar dengan jumlah hewan peliharaan mencapai sekitar 21 ekor saat ini dikembangkan di penangkaran Aro-M di Bumi Marina, Manokwari.

Pengetahuan yang mendalam mengenai biologi reproduksi dari rusa tropik yang ditangkarkan pada habitat aslinya masih sangat terbatas. Penelitian pendahuluan tingkah laku sosial sebagai bagian dari pengembangan penangkaran rusa telah dilakukan oleh Madja et al. (2018). Pada kelompok rusa, telah diketahui bahwa pada musim kawin, pejantan akan berkompetisi dengan pejantan lain untuk dapat menguasai kelompok betina yang dapat dikawininya. Sifat mengumpulkan beberapa ekor betina oleh seekor pejantan disebut pengumpulan harem (Semiadi dan Nugraha, 2004). Pengetahuan tentang perkawinan rusa yang baik diharapkan mampu mengurangi resiko akibat perkelahian antar pejantan selama perebutan atau kompetisi dalam mengawini rusa betina yang berahi.

Penampakan ekor yang berdiri tegak merupakan ciri rusa betina yang sedang berahi, dan semakin sering terjadi saat menjelang bulan purnama (Semiadi, 1996). Menurut penelitian Nalley (2006) urin yang dihasilkan rusa betina mengandung pheromon dan sekresi organ reproduksi seperti lendir serviks. Selanjutnya dijelaskan bahwa rusa betina yang estrus menunjukkan tingkat laku urinasi yang frekuensinya cukup tinggi $(25,11 \pm 7,19$ kali/detik).

Penelitian ini dilakukan untuk mengetahui tingkah laku kawin rusa timor (Cervus timorensis) betina dalam kondisi penangkaran yang lebih luas dengan jumlah populasi hewan peliharaan yang relatif banyak berdasarkan aktivitas urinasi dan penampakan ekor yang berdiri tegak pada rusa betina sebagai indikator tingkah laku kawin.

\section{MATERI DAN METODE}

Penelitian berlangsung selama bulan September 2017 di penangkaran rusa timor Aro-M di Kompleks Perumahan Bumi Marina, Kelurahan Amban, Kabupaten Manokwari. Waktu efektif pengambilan data di penangkaran yaitu selama 15 (lima belas) hari.

Lima belas ekor rusa timor betina dewasa digunakan dalam penelitian ini. Penelitian menggunakan metode Time sampling menurut Martin dan Bateson (1988) yang juga digunakan oleh Wirdateti et al. (2005) yaitu dengan teknik pengamatan (observasi) langsung di lapangan. Teknik penelitian dilakukan dengan mengamati dan mencatat penampakan ekor berdiri tegak (Semiadi, 1996) dan aktifitas urinasi (Setiawan et al., 2015) pada rusa betina. Pengamatan dilakukan pada pagi hari yaitu dari pukul 06:00 sampai dengan sore hari pukul 18:00 WIT. Pengamatan dibagi menjadi enam periode waktu dalam satu hari yaitu pukul 06:00-08:00; 08:00-10:00; 10:0012:00; 12:00-14:00; 14:00-16:00 dan 16:0018:00. Pencatatan terhadap perilaku rusa betina dilakukan setiap 20 menit dengan periode jeda 10 menit, sampai setiap periode pengamatan (dua jam) berakhir dalam setiap hari, selama 15 hari pengamatan.

\section{ANALISIS DATA}

Analisis kuantitatif digunakan untuk mengetahui persentase perilaku yang dapat dihitung dengan menggunakan rumus sebagai berikut (Martin dan Batcson 1988): 


\author{
Frekuensi suatu perilaku $(\%)=\frac{\boldsymbol{A}}{\boldsymbol{B}} \boldsymbol{x} \mathbf{1 0 0} \%$ \\ Keterangan: \\ $\mathrm{A}=$ Frekuensi suatu perilaku dalam satu periode pengamatan \\ $\mathrm{B}=$ Jumlah frekuensi semua perilaku dalam satu periode pengamatan.
}

\section{HASIL DAN PEMBAHASAN}

\section{KEADAAN UMUM PENANGKARAN}

Penangkaran rusa timor Aro-M di Bumi Marina, berdiri sejak tahun 2015 dan memiliki luas $126 \times 96 \mathrm{~m}$. Tempat bernaung rusa tersedia dengan ukuran $25 \times 5 \mathrm{~m}$, dengan areal sisanya adalah padang hijauan (Gambar 1), yang ditumbuhi hijauan pakan seperti rumput lapangan/karpet (Axonopus compressus), rumput teki (Cyperus rotundus L.) rumput jarum (Chrysopogon aciculatus). Saat dilakukan penelitian, jumlah rusa yang dipelihara sebanyak 21 ekor. Ada 6 ekor rusa

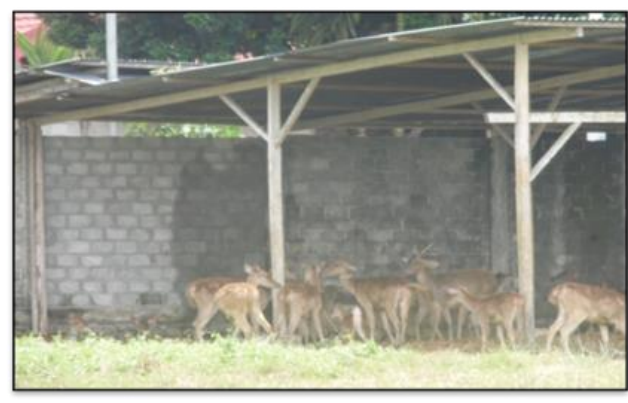

Gambar 1. Tempat umbaran rusa. Kiri: Tempat bernaung; Kanan: Padang hijauan pakan

\section{URINASI}

Tabel 1 menunjukan bahwa persentase urinasi tertinggi terjadi antara jam 08.00-10.00. Hasil pengamatan (Gambar 2), menunjukkan bahwa frekuensi urinasi rusa betina terendah $(12,37 \%)$ terjadi pada periode jam $10.00-12.00$ sedangkan yang paling tinggi $(22,22 \%)$, pada periode jam 08.00-10.00. Aktivitas jantan seperti mengendus, mencium dan menjilat organ genital betina membantu terjadinya urinasi akibat peningkatan hormon estrogen Nalley (2006). Hal ini juga teramati pada saat penelitian walaupun pejantan bukan merupakan objek pengamatan. Hal mana terlihat reaksi betina melalui aktivitas urinasi terjadi setelah pejantan melakukan pendekatan dan mencium bagian genital betina akibat meningkatnya produksi urin. Hal yang sama juga dicatat oleh jantan yang terdiri dari 1 ekor anakan, 4 ekor remaja dan 1 ekor dewasa, 15 ekor betina dewasa.

Pemeliharaan rusa di penangkaran Aro-M dilakukan dengan cara diumbar (ekstensif) di dalam area penangkaran. Kebutuhan air minum bagi rusa peliharaan disediakan dari sumur yang dialirkan ke tempat minum di dalam penangkaran melalui pipa, biasanya dilakukan setiap pukul 08.00 pagi.

Pengamatan terhadap aktivitas urinasi dan penampakan ekor berdiri tegak rusa betina disajikan pada Tabel 1 dan Gambar 2 .

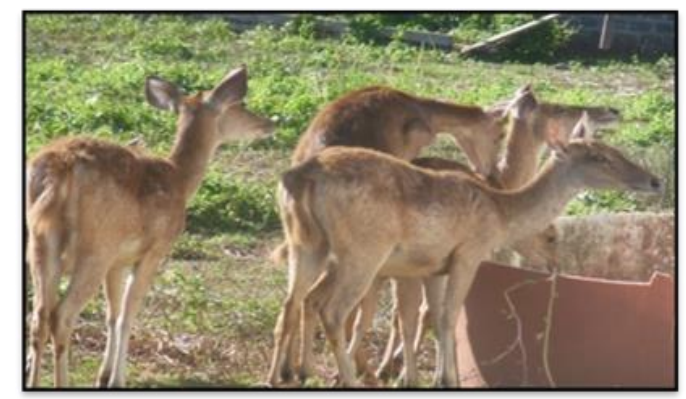

Wirdateti et al. (2005) pada kelompok rusa yang dipelihara di perkebunan kelapa PT Kuala Tembaga.

Kami tidak melakukan pengamatan berapa lama waktu yang dibutuhkan untuk sekali aktivitas urinasi, tetapi Setiawan dkk (2015) menjelaskan bahwa frekuensi urinasi pada saat berahi cukup tinggi dengan jumlah urin yang tidak terlalu banyak. Jumlah urin yang dihasilkan bisa banyak pada saat betina terangsang oleh sentuhan pejantan.

Menurut Nalley (2006) bahwa aktivitas rusa jantan seperti mengendus, mencium dan menjilat organ genital betina membantu terjadinya urinasi akibat peningkatan hormon estrogen. Hasil pengamatan menunjukkan bahwa reaksi rusa betina melalui aktivitas urinasi terjadi setelah pejantan melakukan pendekatan dan mencium bagian genital betina 
akibat meningkatnya produksi urine. Hasil yang sama juga dilaporkan oleh Wirdateti et al.,
(2005) pada kelompok rusa yang dipelihara di perkebunan kelapa PT Kuala Tembaga.

Tabel 1. Frekuensi dan persentase urinasi dan penampakan ekor berdiri tegak rusa timor betina di penangkaran Aro-M

\begin{tabular}{|c|c|c|c|c|c|c|c|c|}
\hline \multirow[b]{2}{*}{ Aktivitas } & \multicolumn{6}{|c|}{ Frekuensi (x)/Periode Waktu } & \multirow{2}{*}{$\begin{array}{c}\text { Total } \\
\text { Perilaku }\end{array}$} & \multirow{2}{*}{$\begin{array}{c}\text { Rataan } \\
\text { Perilaku } \\
\quad(\%)\end{array}$} \\
\hline & $\begin{array}{c}\text { 06:00- } \\
08: 00\end{array}$ & $\begin{array}{l}\text { 08:00- } \\
10: 00\end{array}$ & $\begin{array}{l}10: 00- \\
12: 00\end{array}$ & $\begin{array}{l}12: 00- \\
14: 00\end{array}$ & $\begin{array}{c}14: 00- \\
16: 00\end{array}$ & $\begin{array}{c}16: 00- \\
18: 00\end{array}$ & & \\
\hline Urinasi & 16,00 & 18,00 & 10,00 & 14,00 & 12,00 & 11,00 & 81,00 & 18,62 \\
\hline$\%$ & 19,75 & 22,22 & 12,35 & 17,28 & 14,81 & 13,58 & & \\
\hline Penampakan ekor berdiri tegak & 94,00 & 69,00 & 32,00 & 29,00 & 80,00 & 50,00 & 354 & 81,38 \\
\hline$\%$ & 26,55 & 19,49 & 9,04 & 8,19 & 22,60 & 14,12 & & \\
\hline Total Perilaku & 110 & 87 & 42 & 43 & 92 & 61 & 435 & \\
\hline Rataan Perilaku (\%) & 25.29 & 20.00 & 9.66 & 9.89 & 21.15 & 14.02 & & \\
\hline
\end{tabular}

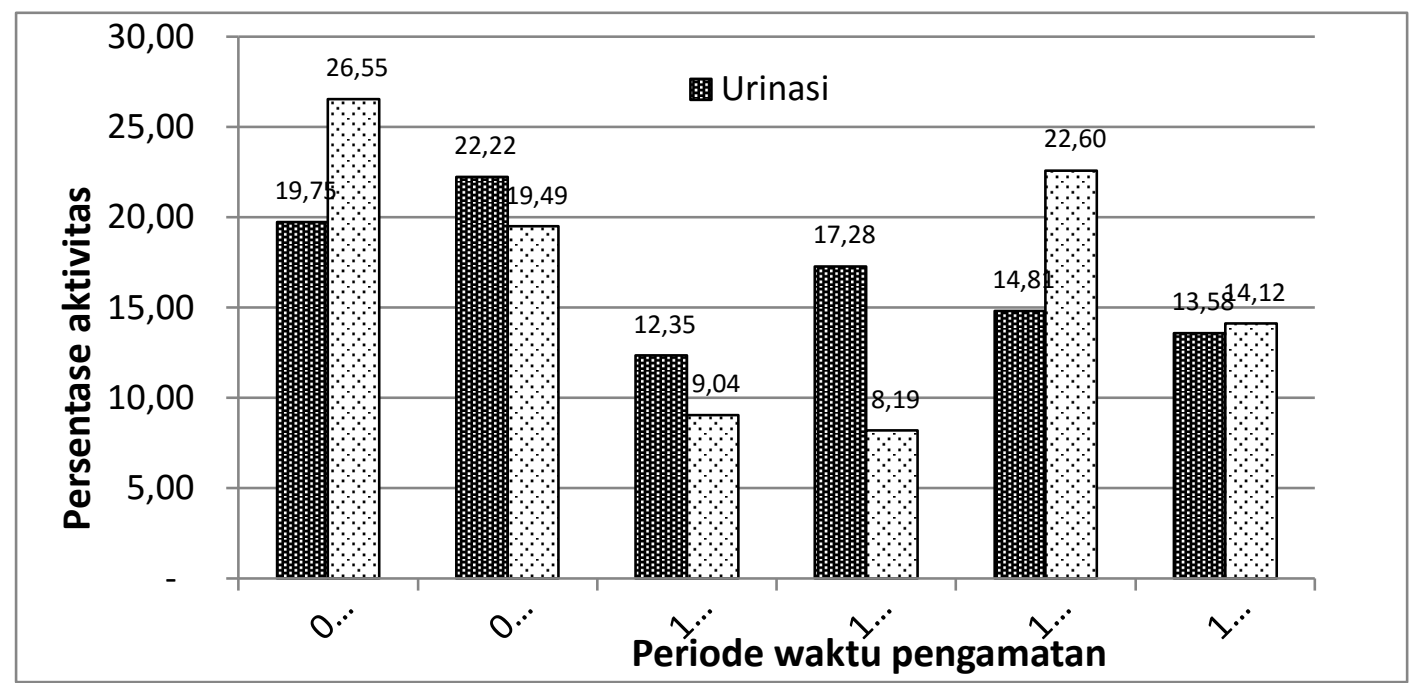

Gambar 2. Persentase aktivitas urinasi dan penampakan ekor berdiri tegak rusa timor betina yang diamati

Pada penelitian ini tidak dilakukan pengamatan lama waktu yang dibutuhkan untuk sekali aktitivitas urinasi, tetapi Setiawan et al. (2015) menjelaskan bahwa frekuensi urinasi pada saat berahi cukup tinggi dengan jumlah urine yang tidak terlalu banyak. Tetapi jumlah urine yang dihasilkan bisa banyak pada saat betina terangsang oleh sentuhan pejantan.

Menurut Nalley (2006), urin yang dikeluarkan betina juga mengandung pheromon dan sekresi vagina yang berfungsi untuk memberikan indikasi pejantan terhadap betina yang memasuki masa estrus dan menjadi penciri dari yang sedang tidak mengalami masa estrus. Hal ini menunjukan bahwa urin yang diproduksi rusa betina adalah indikator agar rusa jantan mendekati rusa betina akibat kandungan feromon dan sebagian kecil produksi sekresi organ reproduksi yaitu lendir serviks. Frekuensi urinasi yang terjadi pada saat estrus lebih banyak daripada saat tidak sedang estrus. Nalley (2006) menjelaskan bahwa rusa betina yang estrus menunjukkan tingkah laku urinasi yang frekuensinya cukup tinggi.

\section{PENAMPAKAN EKOR BERDIRI TEGAK}

Penampakan ekor berdiri tegak merupakan aktivitas yang simultan dengan urinasi. Dalam pengamatan, penampakan ekor yang berdiri tegak (Gambar 2), paling sering terjadi pada periode pukul $06.00-08.00$ yaitu $(26,55 \%)$, dan terendah $(8,19 \%)$, terlihat pada pukul 12.00 14.00. Penampakan ekor ini juga merupakan usaha untuk menarik perhatian pejantan. Selama penelitian terlihat bahwa ciuman atau jilatan pejantan pada daerah sekitar genitalia betina memicu terjadinya ekor berdiri tegak. Hal ini sering terjadi di pagi hari saat kelompok rusa baru mulai melakukan aktivitasnya. Hasil penelitian Balitbang Peternakan (1996) menunjukkan bahwa penampakan ekor yang berdiri tegak sebagai ciri rusa betina yang sedang berahi. 


\section{KESIMPULAN}

Aktivitas urinasi dan penampakan ekor berdiri tegak merupakan indikator birahi rusa berina dan siap untuk dikawini pejantan. Frekuensi urinasi rusa betina terendah $(12,37 \%)$ terjadi pada periode pukul 10.00 12.00 , sedangkan yang paling tinggi $(22,22 \%)$ pada periode pukul 08.00-10.00. Penampakan ekor yang berdiri tegak paling sering terjadi pada periode pukul 06.00-08.00 yaitu $(26,55 \%)$, dan terendah $(8,19 \%)$, teramati pada pukul 12.00-14.00. Dalam penelitian ini pengamatan hanya dilakukan pada rusa betina, tetapi hasil pengamatan menunjukkan kontribusi rusa jantan ikut mempengaruhi aktivitas urinasi dan penampakan ekor berdiri tegak pada rusa betina.

\section{UCAPAN TERIMA KASIH}

Ucapan terima kasih disampaikan kepada Dr. Frans Tan yang telah mengijinkan penulis melakukan penelitian di fasilitas penangkaran Aro-M.

\section{DAFTAR PUSTAKA}

Drajat A. S. 2002. Satwa Harapan: Mataram University Press. Mataram

Duwila R. 2001. Sistem Pemeliharaan dan Ukuran Statistik Vital rusa timor (Cervus timorensis) di Kabupaten Manokwari. Skripsi. Fakultas Peternakan. Universitas Negeri Papua. Manokwari.

Garsetiasih R. dan Tekandjanji M. 2007. Model Penangkaran Rusa. Prosiding Ekspose Hasil-Hasil Penelitian.

Ismail D. 2002. Kajian Tingka Laku Dan Kinerja Reproduksi Rusa (Cervus timorensis) Yang Dipelihara Di Penangkaran Cariun Dan Ranca Upas Jawa Barat. Disertasi. Universitas Padjadjaran Bandung.

Madja J. T., Koibur J. F. dan Pattiselanno F. 2018. Tingkah laku sosial rusa timor
(Cervus timorensis) di Penangkaran Bumi Marina, Manokwari. Jurnal Ilmu Peternakan dan Veteriner Tropis. 8(2): 5155

Martin P. and Bateson P. 1988. Measuring Behavior: An Introductory Guide. $2^{\text {nd }} E d$. Cambridge University Press, Cambridge, USA.

Nalley M. W. M. 2006. Study on biology of reproduction and application of artificial insemination technology on timor deer (Cervus timorensis). Dissertation. Graduate School Bogor Agriculture University, Bogor.163p

Pattiselanno F. 2003. Deer (Cervidae: Artiodactyla: Mammalia) wildlife potential with future expectations. Tigerpaper. 30(3): 13-16

Pattiselanno F., Isir D., Takege A. dan Seseray D. 2008. Kajian Awal Penangkaran Rusa (Cervus timorensis) Sistem Back Yard di Manokwari, Papua Barat. Biosfera 25 (2): 95-100

Semiadi G. 1996. Tatalaksana pemeliharaan rusa timorensis (Cervus timorensis) oleh masyarakat di Pulau Timor. Prosiding Seminar Nasional Peternakan dan Veteriner. Pusat Penelitian dan Pengembangan Peternakan.

Semiadi G. dan Nugraha T. P. 2004. Panduan Pemeliharaan Rusa Tropis. Pusat Penelitian Biologi Lembaga Ilmu Pengetahuan Indonesia.

Setiawan I. A., Samsudewa D. dan Sutiyono. 2015. Pengaruh jumlah pejantan per kandang terhadap tingkah laku reproduksi rusa timor (Rusa timorensis) betina. Agromedia. 33(2): 71-77.

Wirdateti M. dan Kundarmaso A. 2005. Pengamatan tingkah laku rusa timor (Cervus timorensis) di PT Kuala Tembaga, Desa Aertembaga Bitung - Sulawesi Utara. Animal Production. 7(2): 121-126 